\title{
Anti-OFA Immunotherapeutic BB-MPI-03
}

National Cancer Institute

\section{Source}

National Cancer Institute. Anti-OFA Immunotherapeutic BB-MPI-03. NCI Thesaurus.

Code C118368.

A cancer vaccine composed of 3 different cytotoxic T-cell epitopes derived from the tumor-associated antigen oncofetal antigen (OFA), with potential immunostimulating and antineoplastic activities. Upon intradermal administration, anti-OFA immunotherapeutic vaccine BB-MPI-03 activates the immune system to elicit a specific cytotoxic Tlymphocyte (CTL) response against tumor cells expressing OFA. OFA, also called immature laminin receptor protein (iLRP), is expressed in fetal tissues and is overexpressed in various cancers; its expression is correlated with cancer cell survival. 